\title{
Altruism and the Demand for Environmental Quality
}

\author{
December 13, 1999
}

\author{
David Popp \\ Department of Economics \\ The University of Kansas \\ 213 Summerfield Hall \\ Lawrence, KS 66045-2113 \\ tel: (785) 864-2868 \\ fax: (785) 864-5270 \\ dpopp@ukans.edu
}

\begin{abstract}
This paper asks whether individuals consider the value future generations will receive from environmental quality when deciding what level of environmental protection to provide. Using data on life expectancy, I develop two tests for altruism towards future generations. One, a test for strong altruism, assumes that individuals place no consideration on their own self-interest when deciding to provide environmental quality. The second, a test for weak altruism, combines an individual's concern for both self-interest and the interest of future generations. Using data from a Washington Post survey on environmental attitudes to implement the test, evidence of weak altruism is found.
\end{abstract}

The author would like to thank William Nordhaus and Dietrich Earnhart for helpful comments. As usual, any remaining errors are the responsibility of the author. 


\title{
Altruism and the Demand for Environmental Quality
}

\begin{abstract}
This paper asks whether individuals consider the value future generations will receive from environmental quality when deciding what level of environmental protection to provide. Using data on life expectancy, I develop two tests for altruism towards future generations. One, a test for strong altruism, assumes that individuals place no consideration on their own self-interest when deciding to provide environmental quality. The second, a test for weak altruism, combines an individual's concern for both self-interest and the interest of future generations. Using data from a Washington Post survey on environmental attitudes to implement the test, evidence of weak altruism is found.
\end{abstract}




\section{Introduction}

What motivates people to demand higher environmental quality? Do desires for an improved environment come merely from self-interest, or do altruistic motives play a role as well? Using aggregate voting data, Holmes (1990) concludes that altruistic motives do influence the voting decision. This conclusion contrasts with a similar study by Deacon and Shapiro (1975) which concluded that altruism does not play an important role in such decisions. This paper will attempt to rectify the discrepancy between these earlier studies, using a referendum-style survey on taxes and environmental quality. In particular, the paper uses information on life expectancy to develop a test of altruistic demand for preservation of the environment based on concern for the welfare of future generations.

The question of whether altruistic motives play a role in decisions about environmental quality demanded is important for two reasons. First, it helps to determine how an individual's utility function should be defined. Pursuing environmental objectives for altruistic reasons is not inconsistent with the concept of maximization of utility if the utility function is defined so that utility is a function of the welfare of others. If altruistic motives do exist for protecting the environment, methods that attempt to place a value on natural resources must take these motives into account.

On the other hand, if altruistic motives do not play a role in individual decision making, government intervention may be necessary to assure that future generations will be able to enjoy the amount of environmental quality that they desire. For example, when considering the welfare of future generations, the problem is one of missing markets, since future generations will be affected by environmental degradation today, but have no say in how much environmental degradation takes place. Furthermore, even if concern for future generations is found to exist among current generations, using a lower social discount rate would be consistent with individual preferences if there were reason to believe that similar altruistic concerns were not expressed in the marketplace. Concern for future generations has led some economists to argue that the social 
discount rate used in such situations should be lower than the private discount rate observed in market transactions. ${ }^{1}$

The paper begins by contrasting the results of the Deacon and Shapiro (1975) and Holmes (1990) papers. In section three, a formal theory of altruism is presented, which leads to the presentation of the empirical test to be carried out in this paper. The results of a Washington Post survey on the environment are used to test the hypothesis. Section four discusses estimation of the model and the data used. Section five presents the results of estimation. The paper concludes with a discussion of the results and their implications.

\section{Previous Work on Altruism and Environmental Protection}

The paper by Deacon and Shapiro (1975) was among the first to look at the results of voting on referenda as a way of revealing preferences for public goods. They conclude that individuals are motivated by self-interest in demanding public goods. Holmes (1990) extends the basic voting model presented in Deacon and Shapiro (1975) to make explicit provisions for altruism. He creates a proxy variable for altruism, which he finds to be significant. Thus, Holmes (1990) concludes that altruism affects the demand for public goods.

Both the Holmes (1990) study and the Deacon and Shapiro (1975) study use an individual's votes on referenda as revealing a preference for or against more environmental protection. Deacon and Shapiro (1975) look at voting on two California referenda: the 1972 Coastal Zone Conservation Act and the 1970 Rapid Transit Initiative. Holmes (1990) examines voting on California's Safe Drinking Water and Toxic Enforcement Act of 1986. Since individual votes are not recorded, both use aggregate data. Deacon and Shapiro (1975) examine voting results by city, and Holmes (1990) uses county voting records. The results of the votes in each jurisdiction are regressed on the mean attributes of the citizens of the jurisdiction, such as income.

The two papers use different approaches to reach their conclusions on altruism. Deacon and Shapiro (1975) regress the voting results on both personal characteristics, such as income and

\footnotetext{
${ }^{1}$ For example, Weitzman (1998) argues that the lowest possible discount rate should be used for projects affecting the far-distant future.
} 
education, and characteristics which are meant to demonstrate self-interest. For example, in examining the Coastal Zone Conservation Act results, they include dummy variables which represent the distance from the coast for each city. Since the coefficients of the self-interest variables are significant and positive, Deacon and Shapiro (1975) conclude that voters are motivated by self-interest, and that evidence of altruism does not exist. That is, Deacon and Shapiro (1975) test to see whether individual's votes are consistent with maximizing their own self-interest.

In contrast, Holmes (1990) includes both personal characteristics and proxies for altruistic motives in his regression. Following Kau and Rubin (1979), Holmes (1990) uses the residuals from a regression of self-interest on voting behavior as a proxy for ideology. He considers votes cast for Senator in the same election as the Safe Drinking Water referendum. He includes several variables representing self-interest, such as income and the percentage of agricultural workers in a county, in a regression explaining votes for Senator Alan Cranston, a Democrat with a strong environmental record. The residual from this regression is interpreted as a measure of ideology. That is, a positive error term (someone who voted for Cranston although self-interest would predict that they would not) is interpreted as an ideological leaning towards Cranston's more liberal political views. Holmes (1990) then uses this proxy variable in a separate regression on votes for the Safe Drinking Water referendum. Since the coefficients of these dummy variables are significant, Holmes (1990) concludes that altruism is a factor in voting on environmental referenda.

This paper extends the results of these studies by using survey data, rather than voting data, so that individual preferences can be observed. By doing so, more direct measures of altruism can be used. In particular, I examine a specific type of altruism: protecting the environment for future generations. Information on the life expectancy of individual respondents is used to determine the present value of benefits from an environmental project that they can expect to receive in their lifetime. The benefits of environmental protection accrue for many years after the initial expenditure. Thus, if people are motivated only by self-interest, we would expect 
the amount individuals are willing to pay for environmental protection to fall as life expectancy decreases, since older people will not be alive to enjoy the benefits of preserving resources for later years. In contrast, if caring for the environment was also motivated by a concern for future generations, this would not be the case.

\section{A Theory of Altruism}

This paper attempts to determine whether people are altruistically motivated in the provision of public goods. In particular, the paper focuses on protection of the environment for future generations. To begin, we need to define altruism in a way that can be empirically tested. In its most general sense, the implication of altruism in economics is that an individual's utility depends not only on her own welfare, but on the welfare of others as well. Define a utility function such as:

$$
U_{i}=U_{i}\left[x_{1 i}, \ldots, x_{m i}, \psi\left(U_{j}\right)\right],
$$

where $i \neq j, x_{z i}$ is the $z$ th commodity consumed by $i$, and $\psi$ denotes that $i$ 's utility is also a function of other people's utility. As long as $\partial U_{i} / \partial U_{j}>0$, so that individual $i$ 's utility increases as the utility of $j$ increases, we could consider individual $i$ to be altruistic.

I proceed by examining equation (1) more closely. Herbert Simon (1993) notes that when economists simply state that individuals maximize utility without postulating what utility is, it is impossible to distinguish altruistic behavior from selfish behavior. Simon suggests a definition of altruism borrowed from evolutionary science. In evolutionary theory, an altruistic act is one that reduces an actor's own fitness while enhancing the fitness of others. This definition can readily be adapted to utility theory. Consider a transfer of one unit of a good from person $i$ to person $j$. If the good is of value to both people, the transfer increases the utility of person $j$. In addition, the utility person $i$ gains from consumption of the good falls. What motivates $i$ to make this transfer? Presumably the loss $i$ suffers from having less of the good is offset by the gain $i$ enjoys from knowing that $j$ 's utility has increased. Thus, it's not that $i$ necessarily suffers a loss of utility that makes the act altruistic, as Simon proposes, but that $i$ would suffer a loss of utility if we ignore 
the gain $i$ enjoys by knowing that $j$ 's utility has increased. ${ }^{2}$ Even though the overall utility of $i$ increases, the act should not be viewed as selfish, because $j$ ' s utility has also increased. Defining altruism in this way has the advantage that it explains altruism using individual rationality. (Becker 1976)

In this paper, I focus on altruistic preservation of the environment for future generations. In particular, I test whether the valuation that individuals place on an environmental project consists only of the value that they will enjoy during their lifetimes, or if the value that future generations will receive is also taken into account. To test for altruistic motives, I look at the relationship between life expectancy and willingness to pay for environmental conservation. Consider, for example, a public project to reduce air pollution. Assume that the project will produce an annual stream of benefits, valued by a representative agent of type $i$ at $v_{i}(x)$, for several years, and that these benefits are discounted at the rate $r .^{3}$ The value, $v_{i}$, placed on the project by each agent depends on individual characteristics, denoted as $x_{i}$. For example, assuming that environmental quality is a normal good, one would expect individuals with higher incomes to place a higher valuation on environmental goods. The present value of these benefits is the following:

$$
P V_{i}=\int_{t=0}^{T} v_{i}\left(x_{i}\right) e^{-r t} d t
$$

where $T$ is the number of years over which benefits will be enjoyed. To make the argument clearer, assume that the benefits of a project are permanent. If an individual cares about the welfare of her offspring, as well as her own welfare, $T=\infty$.

First, consider a case in which individuals are motivated only by self-interest. If this is the true motive of individuals, the amount that individuals are willing to pay for the project should fall

\footnotetext{
${ }^{2}$ For an example in environmental economics, consider Solow's (1993) definition of sustainable conservation, in which conservation is sustainable only if it comes at the expense of current consumption.

3 These benefits may consist solely of the direct benefits an individual places on environmental quality, or they may more generally consist of a valuation that includes the benefits enjoyed by everyone during the current year. That is, this paper abstracts from altruistic behavior towards others alive today to focus on altruism for future generations.
} 
as they age, since the number of years which they can expect to live, and thus enjoy benefits from the project, will be smaller. Mathematically, we have the following:

$$
P V_{i=} \int_{t=0}^{L E_{i}} v_{i}\left(x_{i}\right) e^{-r t} d t=\frac{v_{i}\left(x_{i}\right)}{r}\left(1-e^{-r L E_{i}}\right) \text {. }
$$

Since $L E_{i}$ is smaller for older individuals, if individual $i$ is older than individual $j, P V_{i}<P V_{j}$. In the limit, as one's life expectancy goes to zero, we would expect the willingness to pay to go to zero. Plotting willingness to pay on the vertical axis, and life expectancy on the horizontal, Figure 1 shows that the willingness to pay for the project increases as life expectancy increases, and asymptotes towards $v_{i}\left(x_{i}\right) / r$ as life expectancy approaches infinity.

Now consider a case in which individuals consider the entire stream of benefits the project gives to society. Such individuals are willing to pay not only for benefits that occur while they are alive, but also for benefits that future generations will receive as well. The present value is:

$$
P V_{i=} \int_{t=0}^{\infty} v_{i}\left(x_{i}\right) e^{-r t} d t=\frac{v_{i}\left(x_{i}\right)}{r}
$$

Equation (4) is identical to equation (3), except that, since the individual cares about the benefits provided to future generations, the summation of annual values continues to infinity, rather than stopping at the end of one's life. Thus, other things being equal, individuals should be willing to pay the same for the project no matter how many years they expect to live. As illustrated in Figure 2, willingness to pay is not a function of life expectancy in this case. Note, however, that the perceived value of the project is still a function of other variables relating to self-interest. For example, the amount of income that one person has influences the amount they are willing to pay for altruistic causes.

If equation (4) holds, individuals are sacrificing current income to pay for a project whose benefits will be enjoyed by future generations even after the individual has died and can no longer enjoy the benefits herself. Such a case fits the definition of altruism defined earlier. For the remainder of the paper, this scenario, in which we observe a zero slope in the relationship between life expectancy and willingness to pay will be referred to as the strong form of altruism. 
One can also consider a weaker form of altruism. Suppose that individuals do care about the needs of future generations, so that willingness to pay is positive as life expectancy goes to zero. However, suppose also that these individuals consider their welfare to be more important than that of future generations. Thus, the present value of a project is greater for those whose life expectancy is higher. Define $\alpha_{i}$ as the weight that an individual places on her self-interest value. The present value of the benefits of the project for person $i$ can be written as:

$$
P V_{i}=\alpha_{i} \int_{t=0}^{L E_{i}} v_{i}\left(x_{i}\right) e^{-r t} d t+\left(1-a_{i}\right) \int_{t=0}^{\infty} v_{i}\left(x_{i}\right) e^{-r t} d t, 0 \leq \alpha_{i} \leq 1
$$

The first term of this expression is the same as equation (3). It is the value person $i$ receives from her own consumption of the benefits of the project in the self-interest case. The second term is the benefit the person receives from the project if she demonstrates the strong form of altruism defined in equation (4). The term $\alpha_{i}$ determines how much weight individual $i$ places on his own self interest versus the altruistic value. $\alpha_{i}=1$ corresponds to the purely self interested case, and $\alpha_{i}$ $=0$ corresponds with the purely altruistic case.

Figure 3 illustrates a case where neither strong altruism nor pure self-interest holds. In this example, $\alpha=0.5$. The figure is a combination of the first two figures. Even at a life expectancy of 0 , the individual has a positive willingness to pay, which is equal to one-half of the value with strong altruism. As life expectancy increases, willingness to pay increases asymptotically towards the strong altruism value of $v_{i}\left(x_{i}\right) / r$. Such behavior is altruistic since individuals are forgoing current income for the benefit of future generations. Even those with a life expectancy of zero express a positive willingness to pay. However, unlike the previous case, there is added concern for one's own welfare. This case will be referred to as the weak form of altruism.

I now have two hypotheses that can test for the presence of altruism. First, one can test for strong altruism by simply observing the coefficient of life expectancy when regressed against willingness to pay. The null hypothesis of strong altruism is that this coefficient equals zero. 
However, a positive slope does not lead one to reject the presence of altruism. Rather, a positive slope only means that the strong form of altruism does not exist. In such a case, a second test is necessary to test for the presence of weak altruism. From equation (5), the null hypothesis of purely self-interested behavior holds when $\alpha=1$. Alternatively, the null hypothesis of strong altruism holds when $\alpha=0$. If neither of these hypotheses hold, I conclude that the weak form of altruism exists.

\section{Estimation}

\section{A. Data}

To answer the question of whether altruistic motives lead to demand for environmental quality, I use the results of a March 1990 Washington Post survey on the environment. 1,016 adults aged 18 and over who lived in the 48 contiguous United States or Washington, D.C. were randomly chosen and surveyed by phone. ${ }^{4}$ The survey focused on attitudes toward the environment, although questions on general political beliefs and background information on personal characteristics were also included. The question relevant to this paper is:

"Would you support or oppose a $\$ t$ increase in your personal income taxes that would go just to cleaning up the nation's air and water?"

For one-half of the respondents, $t=\$ 100$, while for the other half, $t=\$ 300$. The values of $t$ were randomly chosen for each respondent.

Had this been a binding vote, rather than a survey, the responses could be viewed as a vote on the above question. Although this is not the case, viewing it as such should not pose a

\footnotetext{
4 The survey was not designed for the purposes of environmental valuation. As such, the results should not be interpreted as accurate valuation of any altruistic tastes, but rather as an illustration of a test of the hypothesis proposed in section III. It is hoped that future researchers will find the proposed methods useful and incorporate them into more carefully designed surveys.
} 
major problem. One concern with using survey data is that respondents are be more likely to respond "yes" than they would if the results were binding. However, the results of the survey are consistent with actual votes observed during the same time period. For both the referendum with $t=\$ 100$ and the one with $t=\$ 300$, a majority of respondents answered "no" when asked if they would allow their taxes to be increased. ${ }^{5}$ Given the actual voting results that November, in which environmental referenda, most notably the "Big Green" referendum in California, did not fare well, such a result seems to be an accurate portrayal of attitudes at the time.

Data on income and education are taken from the survey. Education and income are both grouped variables in this survey. Data for life expectancy is taken from the Statistical Abstract of the United States, published by the U.S. Department of Commerce. The Abstract provides life expectancy for both males and females of different age cohorts. Using data on age and gender from the survey, life expectancy, in years, is calculated for each individual. The responses of individuals who did not answer at least one of the relevant questions were dropped, leaving a total of 951 complete observations to be used.

\section{B. Estimation}

Since individual valuations are not observed in the survey, a probit is used for estimation. A "yes" response will be coded as 1 and a "no" response as 0 . Estimation follows the procedure first discussed in Cameron and James (1987). They use the randomness of the tax rate given to each individual to derive an estimate of the variance of the probability distribution. They are able to do so because they interpret $Y_{i}^{*}$ as individual $i$ 's willingness-to-pay (represented by $P V_{i}$ in this paper) rather than as a difference between the utilities attained in different states. In this approach, the threshold value past which a person answers yes to the referendum varies depending on the tax rate posed to individual $i$. By exploiting this variation, Cameron and James show that it is possible to get direct estimates for $\beta$, as opposed to the traditional probit model, which only allows estimation of $\beta / \sigma$.

\footnotetext{
${ }^{5}$ See the Appendix for a complete description of the data.
} 
The willingness-to-pay approach assumes that individual $i$ will respond "yes" to the referendum if the value that he places on improved environmental quality is greater than the tax rate proposed in the question. The model can be written as:

$$
P V_{i}=\boldsymbol{\beta}^{\prime} \mathbf{X}_{\mathbf{i}}+\varepsilon_{i},
$$

with $\varepsilon_{\mathrm{i}}$ i.i.d. $\mathrm{N}\left(0, \sigma^{2}\right)$. Note that, unlike the traditional probit model, it is not necessary to assume that $\sigma=1$. Because of the variation in $t_{i}$ 's, I am able to identify both $\sigma$ and $\beta$ when I estimate this equation.

To define $\boldsymbol{\beta}^{\prime} \mathbf{X}_{\mathbf{i}}$, a specification of the value function, $v_{i}\left(x_{i}\right)$, introduced in section III is needed. The following relationship is assumed:

$$
v_{i}\left(x_{i}\right)=a+b I N C_{i}+c E D U_{i}{ }^{6}
$$

The test for strong altruism simply includes life expectancy in the function as well:

$$
P V_{i}=a+b I N C_{i}+c E D U_{i}+d L E_{i}+\varepsilon_{i}
$$

The null hypothesis of strong altruism is not rejected if $d=0$.

The test for weak altruism follows from equation (5). To begin, note that equation (5) can be rewritten as:

$$
P V_{i}=\alpha_{i} \frac{v_{i}\left(x_{i}\right)}{r}\left(1-e^{-r L E_{i}}\right)+\left(1-\alpha_{i}\right) \frac{v_{i}\left(x_{i}\right)}{r}
$$

Collecting terms, equation ( $5^{\prime}$ ') simplifies to:

$$
P V_{i}=\frac{v_{i}\left(x_{i}\right)}{r}-\alpha_{i} e^{-r L E_{i}} \frac{v_{i}\left(x_{i}\right)}{r}
$$

Substituting equation (7) for $v_{i}\left(x_{i}\right)$ yields:

$$
P V_{i}=\frac{a}{r}+\frac{b}{r} I N C_{i}+\frac{c}{r} E D U_{i}-\alpha_{i} e^{-r L E_{i}} \frac{a}{r}-\alpha_{i} e^{-r L E_{i}} \frac{b}{r} I N C_{i}-\alpha_{i} e^{-r L E_{i}} \frac{c}{r} E D U_{i}+\varepsilon_{i}
$$

\footnotetext{
6 The location in which a person lived (urban or rural) was also tried as an explanatory variable, but it was found to be insignificant in all regressions, and has thus been excluded in the regressions reported here.
} 
In this scenario, the possible outcomes are:

$$
\begin{aligned}
Y_{i}=0 & \text { if } P V_{i}<t_{i} \\
\text { and } Y_{i}=1 & \text { if } P V_{i} \geq t_{i}
\end{aligned}
$$

The probability of a respondent answering "no" is thus:

$$
\begin{aligned}
\operatorname{Pr}\left(Y_{i}=0\right)=\operatorname{Pr}\left(P V_{i}<t_{i}\right)=\operatorname{Pr} & \left(\boldsymbol{\beta}^{\prime} \mathbf{X}_{\mathbf{i}}+\varepsilon_{\mathrm{i}}<t_{i}\right) \\
& =\operatorname{Pr}\left(\varepsilon_{\mathrm{i}}<t_{i}-\boldsymbol{\beta}^{\prime} \mathbf{X}_{\mathbf{i}}\right) \\
& =\operatorname{Pr}\left(z_{i}<\left(t_{i}-\boldsymbol{\beta} \mathbf{X}_{\mathbf{i}}\right) / \sigma\right) \\
& =\Phi\left(\left(t_{i}-\boldsymbol{\beta}^{\prime} \mathbf{X}_{\mathbf{i}}\right) / \sigma\right),
\end{aligned}
$$

where $z_{i}$ is the standard normal random variable. Similarly, the probability of a "yes" response is:

$$
\begin{aligned}
\operatorname{Pr}\left(Y_{i}=1\right)=\operatorname{Pr}\left(P V_{i \_} t_{i}\right)=\operatorname{Pr} & \left(\boldsymbol{\beta}^{\prime} \mathbf{X}_{\mathbf{i}}+\varepsilon_{\mathrm{i}} \geq t_{i}\right) \\
& =\operatorname{Pr}\left(\varepsilon_{\mathrm{i}} \geq t_{i}-\boldsymbol{\beta} \mathbf{X}_{\mathbf{i}}\right) \\
& =\operatorname{Pr}\left(z_{i} \geq\left(t_{i}-\boldsymbol{\beta} \mathbf{X}_{\mathbf{i}}\right) / \sigma\right) \\
& =1-\Phi\left(\left(t_{i}-\boldsymbol{\beta}^{\prime} \mathbf{X}_{\mathbf{i}}\right) / \sigma\right) .
\end{aligned}
$$

We can now derive the likelihood function necessary to estimate equation (6).

$$
L=f\left(\beta, \sigma \mid \mathbf{X}_{\mathbf{i}}, t\right)=\prod_{i=1}^{N}\left\{\Phi\left(\left(t_{i}-\boldsymbol{\beta}^{\prime} \mathbf{X}_{\mathbf{i}}\right) / \sigma\right)\right\}^{1-Y_{i}}\left\{1-\Phi\left(\left(t_{i}-\boldsymbol{\beta}^{\prime} \mathbf{X}_{\mathbf{i}}\right) / \sigma\right)\right\}^{Y_{i}}
$$

The resulting log-likelihood function is:

$$
\log L=\sum_{i=1}^{N}\left\{\left(1-Y_{i}\right)\left[\log \Phi\left(\left(t_{i}-\boldsymbol{\beta}^{\prime} \mathbf{X}_{\mathbf{i}}\right) / \sigma\right)\right]+Y_{i}\left[\log \left(1-\Phi\left(\left(t_{i}-\boldsymbol{\beta}^{\prime} \mathbf{X}_{\mathbf{i}}\right) / \sigma\right)\right)\right]\right\}
$$

To estimate equation (13), the Goldfeld-Quandt quadratic hill climbing method was used. The log of the tax rate was used to insure that the demand curve implicit in the estimation would be downward sloping (Sellar, Chavas, and Stoll, 1986).

\section{Estimation Results}

I begin by presenting the results of the test for strong altruism. This test uses equation (8) to define the present value of environmental benefits. Recall that strong altruism implies that the coefficient on life expectancy will be zero. Table 1 presents the results of estimation for this regression. Two estimations were carried out: one with and one without education included as an 
explanatory variable, since the education variable proved to be insignificant. ${ }^{7}$ The coefficient in which we are most interested is that of life expectancy. The theory suggests that this coefficient will either be positive or insignificantly different from 0 . The results confirm this. However, what we are most interested is the significance of this coefficient. If it is insignificant, then we fail to reject the null hypothesis that strong altruism exists. If it is significant, we need to test for the presence of the weaker form of altruism.

As Table 1 shows, the results for the null hypothesis that the coefficient of life expectancy is insignificant are unconvincing. The coefficient is insignificant in the regression that includes education, and significant only at the $10 \%$ level in the regression that excludes education. However, one concern is that life expectancy may also proxy for wealth, which is not measured in the data. Elderly individuals with low life expectancies may have little income but greater wealth than those with longer life expectancies. If environmental quality is a normal good, this would work against the hypothesis that life expectancy should have a positive sign. As a result, it seems prudent to test for the weak form of altruism as well, especially since the life expectancy coefficient is close to being significant.

The test for weak altruism is carried out using equation (9) for the present value. $\alpha$ represents the portion of an individual's valuation that is consistent with self-interest behavior, and 1- $\alpha$ represents the portion of the valuation representing altruism towards future generations. Results for the test of the weak form of altruism are shown in Table 2. Two sets of results are given: one using a discount rate of 0.03 for the present value calculation, and a second using a

7 The insignificance of the education coefficient contrasts with the results of Deacon and Shapiro (1975), who found education to have a highly significant positive effect on voting for environmental referenda. Their conclusion is that higher levels of education increase one's awareness of environmental problems. The insignificance of the education coefficient in these results may be evidence of greater awareness of environmental problems in America than was present when Deacon and Shapiro (1975) wrote in the early 1970 's. As a result, no longer is the environment only an issue for the better educated. 
discount rate of 0.05 . These discount rates are consistent with those used in other studies of long-term environmental projects. ${ }^{8}$

These results show that altruism does play a role in the valuation of environmental amenities. However, the estimation of $\alpha$ is imprecise. With a discount rate of $0.03,48$ percent of the present value placed on the environmental clean-up project represents concern for future generations. This figure is statistically different from both one and zero. Both the null hypothesis of strong altruism and the null hypothesis of pure self-interest are rejected. With a discount rate of $0.05,41$ percent of the present value placed on the clean-up project is altruistic. However, the standard errors are such that this is not significantly different from one. Thus, I cannot reject the null hypothesis of pure self-interest with a discount rate of 0.05 .

The sensitivity to the discount rate used is interesting. In general, trial runs show that $\partial \alpha / \partial r<0$. That is, the weight placed on self-interest rises as the discount rate used for the present value calculation rises. If the benefits received by future generations are discounted more, they become less important, and thus greater weight falls on the self-interest component of the valuation.

\section{Discussion}

This paper uses survey data to develop a test for altruism in the valuation of environmental amenities. In particular, the paper develops a test for the hypothesis that current generations are willing to altruistically preserve the environment for future generations. Two tests are developed: one for strong altruism, in which only the societal benefits matter in an individual's willingness to pay, and one for weak altruism, in which individuals show concern for both their own self-interest and the welfare of future generations. The evidence is mixed. Weak altruism is found when a discount rate of 0.03 is used. However, I fail to reject the null hypothesis of self-interest when a

8 Additional regressions were done excluding the education variable. However, the results from those regressions were unreliable. Most notably, omitting the education variable changes the coefficient on income to a negative number. 
discount rate of 0.05 is used. Because the estimate of $\alpha$ is imprecise, future studies with more carefully designed surveys may find more convincing results.

The failure to reject the hypothesis that altruistic concerns for future generations exist when valuing environmental projects has important policy implications. What is the appropriate discount rate for policymakers to use when evaluating projects for which benefits accrue well into the future? Concern for future generations has led some economists to argue that the social discount rate used in such situations should be lower than the private discount rate observed in market transactions. The conclusion that concern for future generations exists implies that this would be in accordance with individual preferences if there was reason to believe that similar altruistic concerns were not expressed in the marketplace. ${ }^{9}$

Finally, a caveat is in order. The survey used to demonstrate the test for altruistic behavior was not designed with contingent valuation in mind. Thus, the results of this paper are best interpreted as a demonstration of the test for altruism presented in section III. It is hoped that others will find the proposed test of interest, and that more carefully designed survey instruments will be used to verify the results of this paper.

\footnotetext{
${ }^{9}$ Economists have offered several reasons as to why altruism may be less pervasive in the marketplace. For example, Krutilla (1967) notes the public goods nature of environmental amenities bequeathed to future generations. Sen (1981) notes that in such a case, the social rate of return and private rate of return will deviate.
} 


\section{Appendix - A Description of the Data}

The data is taken from a March 1990 Washington Post poll. It can be obtained from the Inter-university Consortium for Political and Social Research, Ann Arbor Michigan (ICPSSR \#9456). 1,016 adults aged 18 and older living in the 48 contiguous United States and the District of Columbia were contacted by phone for the survey. Respondents who did not answer any of the relevant questions for this paper were eliminated, leaving 951 observations for analysis. Results of the referendum question for these 951 people are shown in table A1.

Table A1 - Results of the Referendum

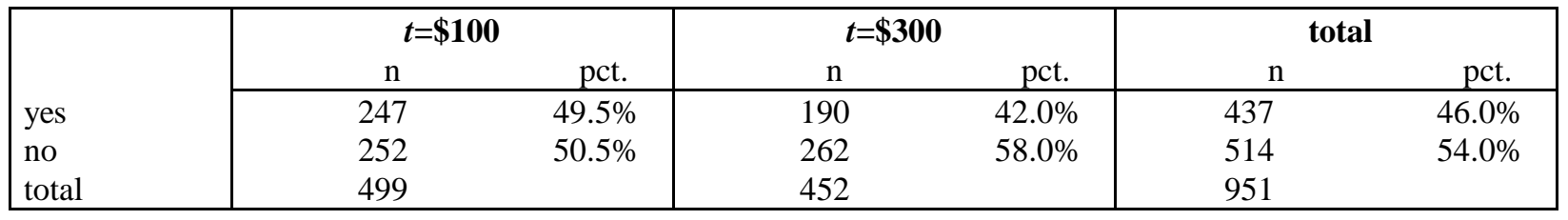

The explanatory variables are defined as follows. Respondents were asked to give their age in years. This information was translated into life expectancy using data from the Statistical Abstract of the United States: 1993. Life expectancy is given in years.

The information on income comes from grouped data. Respondents were asked to place their household's annual income in one of six categories, which were coded as follows:

1) Under $\$ 8,000$

2) $\$ 8,000$ but less than $\$ 12,000$

3) $\$ 12,000$ but less than $\$ 20,000$

4) $\$ 20,000$ but less than $\$ 30,000$

5) $\$ 30,000$ but less than $\$ 50,000$

6) More than $\$ 50,000$

Since the size of these groups is not identical, the median income in each was used. For the first group, $\$ 7,000$ was used, since it seems more likely that individuals would be closer to $\$ 8,000$ than to $\$ 0$. For the last grouping, $\$ 50,000$. Of the nearly 25 percent of the population with income, nearly $2 / 3$ of these were in the range of $\$ 50,000$ to $\$ 75,000$. Thus, choosing a number in this range seems reasonable. To account for the fact that there still are those whose income is higher, a value at the high end of this range was chosen. ${ }^{10}$

\footnotetext{
10 Data on income distributions were taken from the Statistical Abstract of the United States: 1993.
} 
Education was grouped in a similar fashion. The relevant information was the last grade of school completed by the respondent:

1) 8th grade or less

2) Some high school

3) Graduated high school

4) Some college ${ }^{11}$

5) Graduated college

6) Post-graduate

Tables A2-A4 present the descriptive data for the survey. The first two tables present the data for the estimation of the two separate referenda, and the third presents the combined data.

Table A2 - Descriptive Data for Referendum when $t=\$ 100(n=499)$

\begin{tabular}{|llrc|}
\hline Variable & Description & Mean & Std. Dev. \\
INCOME & In 10,000's of dollars & 3.604 & 2.207 \\
LE & Years of life expected, based on respondent's age & 35.673 & 13.790 \\
EDUCATION & Coded value of respondent's education level & 3.697 & 1.243 \\
\hline
\end{tabular}

Table A3 - Descriptive Data for Referendum when $t=\$ 300(n=452)$

\begin{tabular}{|llrr|}
\hline Variable & Description & Mean & Std. Dev. \\
INCOME & In 10,000's of dollars & 3.613 & 2.132 \\
LE & Years of life expected, based on respondent's age & 35.678 & 13.876 \\
EDUCATION & Coded value of respondent's education level & 3.704 & 1.235 \\
\hline
\end{tabular}

Table A4 - Descriptive Data for Combined Referendum (n=951)

\begin{tabular}{|llrc|}
\hline Variable & Description & Mean & Std. Dev. \\
INCOME & In 10,000's of dollars & 3.608 & 2.170 \\
LE & Years of life expected, based on respondent's age & 35.675 & 13.824 \\
EDUCATION & Coded value of respondent's education level & 3.700 & 1.239 \\
\hline
\end{tabular}

11 Technical schools were coded as 3 , for high school. 


\section{REFERENCES}

Becker, Gary, “Altruism, Egoism, and Genetic Fitness: Economics and Sociobiology,” Journal of Economic Literature, 15, 817-826, (1976).

Cameron, Trudy Ann, and James, Michelle D., "Efficient Estimation Methods for 'Closed-Ended' Contingent Valuation Surveys," The Review of Economics and Statistics, 69, 269-276, (1987).

Deacon, Robert, and Shapiro, Perry, "Private Preference for Collective Goods Revealed Through Voting on Referenda," American Economic Review, 65, 943-955, (1975).

Holmes, Thomas P., "Self-Interest, Altruism, and Health-Risk Reduction: An Economic Analysis of Voting Behavior," Land Economics, 66, 140-149, (1990).

Inter-university Consortium for Political and Social Research, Washington Post Poll, March 1990, ICPSR 9456.

Kau, James B. and Paul H. Rubin, "Self-Interest, Ideology, and Logrolling in Congressional Voting," Journal of Law and Economics, 22, 777-786, (1979).

Krutilla, John, “Conservation Reconsidered,” American Economic Review, 57, 777-786, (1967).

Sellar, Christine, Chavas, Jean-Paul, and Stoll, John R., "Specification of the Logit Model: The Case of Valuation of Nonmarket Goods," Journal of Environmental Economics and Management, 13, 382-390, (1986).

Sen, Amartya, "Approaches to the Choice of Discount Rates for Social Benefit-Cost Analysis," in Discounting for Time and Risk in Energy Policy, Robert Lind, ed., (1983).

Simon, Herbert, “Altruism and Economics," American Economic Review, 83, 156-161, (1993).

Solow, Robert, "Sustainability: An Economist's Perspective," in Economics of the Environment: Selected Readings, Robert Dorfman and Nancy Dorfman, eds., (1993).

United States Department of Commerce, Statistical Abstract of the United States: 1993, (1993).

Weitzman, Martin L., "Why the Far-Distant Future Should Be Discounted at Its Lowest Possible Rate," Journal of Environmental Economics and Management, 36, 201-208, (1998). 
Figure 1 - Willingness to Pay in the Self Interest Case

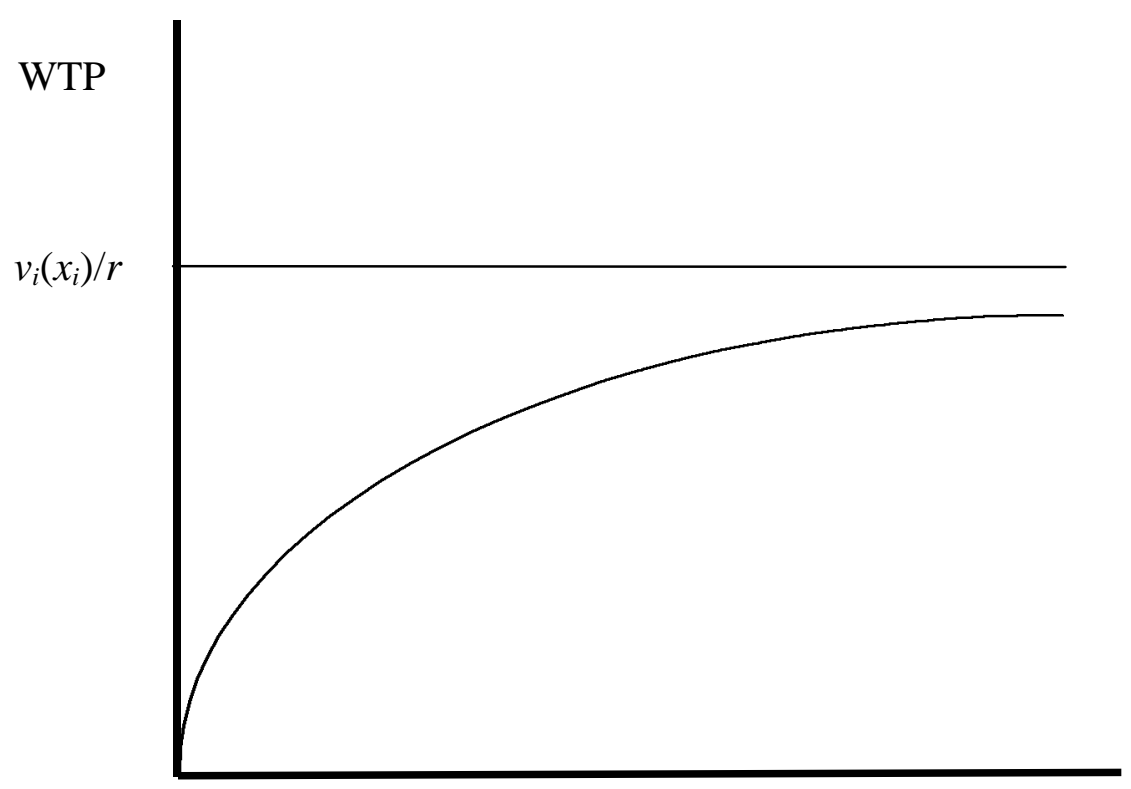

Life Expectancy

Figure 2 - Willingness to Pay - Strong Altruism

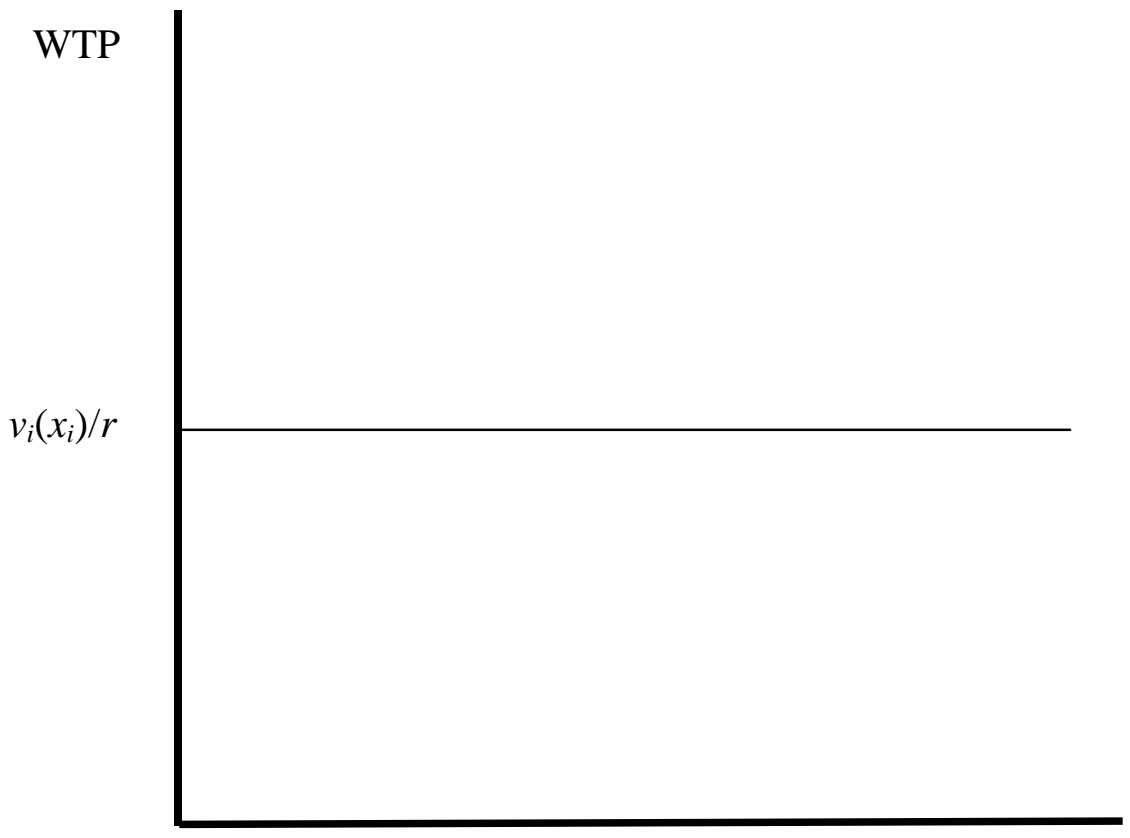

Life Expectancy 


\section{Figure 3 - Willingness to Pay - Weak Altruism}

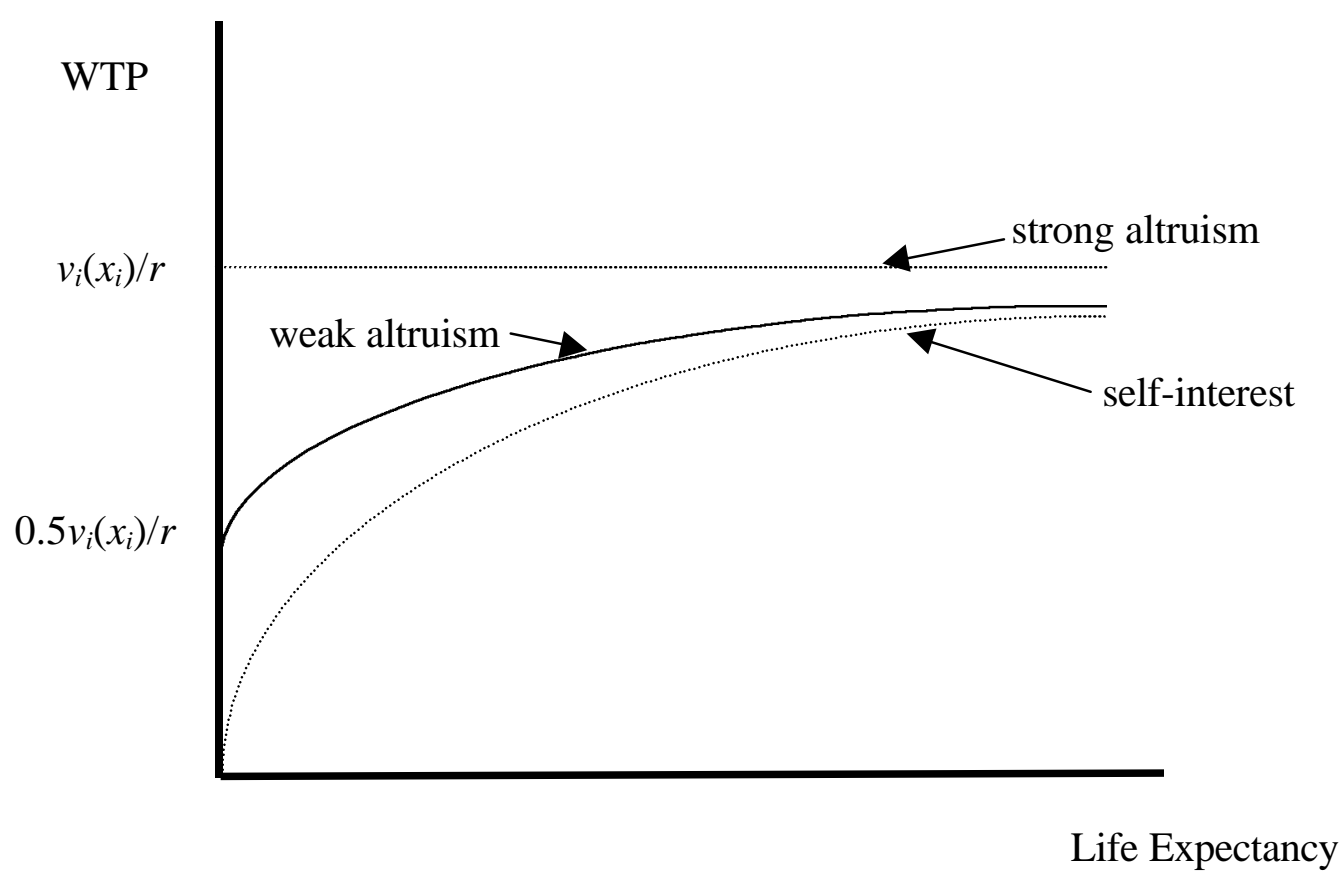

Figure 3 illustrates the case of weak altruism. The dashed lines represent the two polar cases of pure self-interest and strong altruism. The solid line represents the willingness to pay in the case of weak altruism. It is a combination of the two polar cases. In this example, $\alpha=0.5$. Thus, at a life expectancy of 0 , the individual is willing to pay half of what an individual with strong altruism would pay. Nonetheless, willingness to pay increases as life expectancy increases. 
Table 1 - Test for Strong Altruism

\begin{tabular}{|l|ll|ll|}
\hline & $(\mathbf{1})$ & $\boldsymbol{t}$-statistic & $(\mathbf{2})$ & $\boldsymbol{t}$-statistic \\
\hline \hline CONSTANT & 0.840 & 0.413 & 1.348 & 0.765 \\
& $(2.037)$ & & $(1.762)$ & \\
INCOME & $0.457^{* *}$ & 2.016 & $0.501^{* *}$ & 2.114 \\
LE & $(0.227)$ & & $(0.237)$ & \\
& 0.0371 & 1.596 & $0.0385^{* * *}$ & 1.639 \\
EDU & $(0.0232)$ & & $(0.0235)$ & \\
& 0.194 & 0.870 & & \\
SIGMA & $(0.223)$ & & & \\
& $5.620^{* *}$ & 2.338 & $5.611^{* *}$ & 2.346 \\
\hline likelihood & $(2.403)$ & & $(2.392)$ & \\
function: & & & & \\
\hline
\end{tabular}

Note: standard errors in parentheses.

** - significant at the 5\% level.

*** - significant at the $10 \%$ level.

Table 2 - Test for Weak Altruism

\begin{tabular}{|l|ll|ll|}
\hline & $(\mathbf{1})$ & $\boldsymbol{t}$-statistic & $(\mathbf{2})$ & $\boldsymbol{t}$-statistic \\
\hline \hline CONSTANT & $2.901^{* *}$ & 2.034 & $2.722^{* *}$ & 2.049 \\
& $(1.413)$ & & $(1.329)$ & \\
INCOME & $0.503^{* *}$ & 1.985 & $0.454^{* *}$ & 2.093 \\
EDU & $(0.253)$ & & $(0.217)$ & \\
& 0.258 & 0.933 & 0.232 & 0.931 \\
ALPHA & $(0.277)$ & & $(0.249)$ & \\
& $0.524^{* *}$ & 2.002 & $0.590^{* *}$ & 1.848 \\
SIGMA & $(0.262)$ & & $(0.320)$ & \\
& $5.275^{*}$ & 2.738 & $5.260^{*}$ & 2.771 \\
\hline discount rate used & $(1.927)$ & & $(1.898)$ & \\
for PV calculations: & 0.03 & & & \\
\hline \hline $\begin{array}{l}\text { likelihood } \\
\text { function: }\end{array}$ & -638.611 & & \\
\hline
\end{tabular}

Note: standard errors in parentheses.

* - significant at the $1 \%$ level.

** - significant at the 5\% level.

$* * *$ - significant at the $10 \%$ level. 